Document downloaded from:

http://hdl.handle.net/10251/47367

This paper must be cited as:

Martí Vargas, JR.; Caro Forero, LA.; Serna Ros, P. (2013). Experimental Technique for Measuring the Long-term Transfer Length in Prestressed Concrete. Strain. 49(2):125-134. doi:10.1111/str.12019.

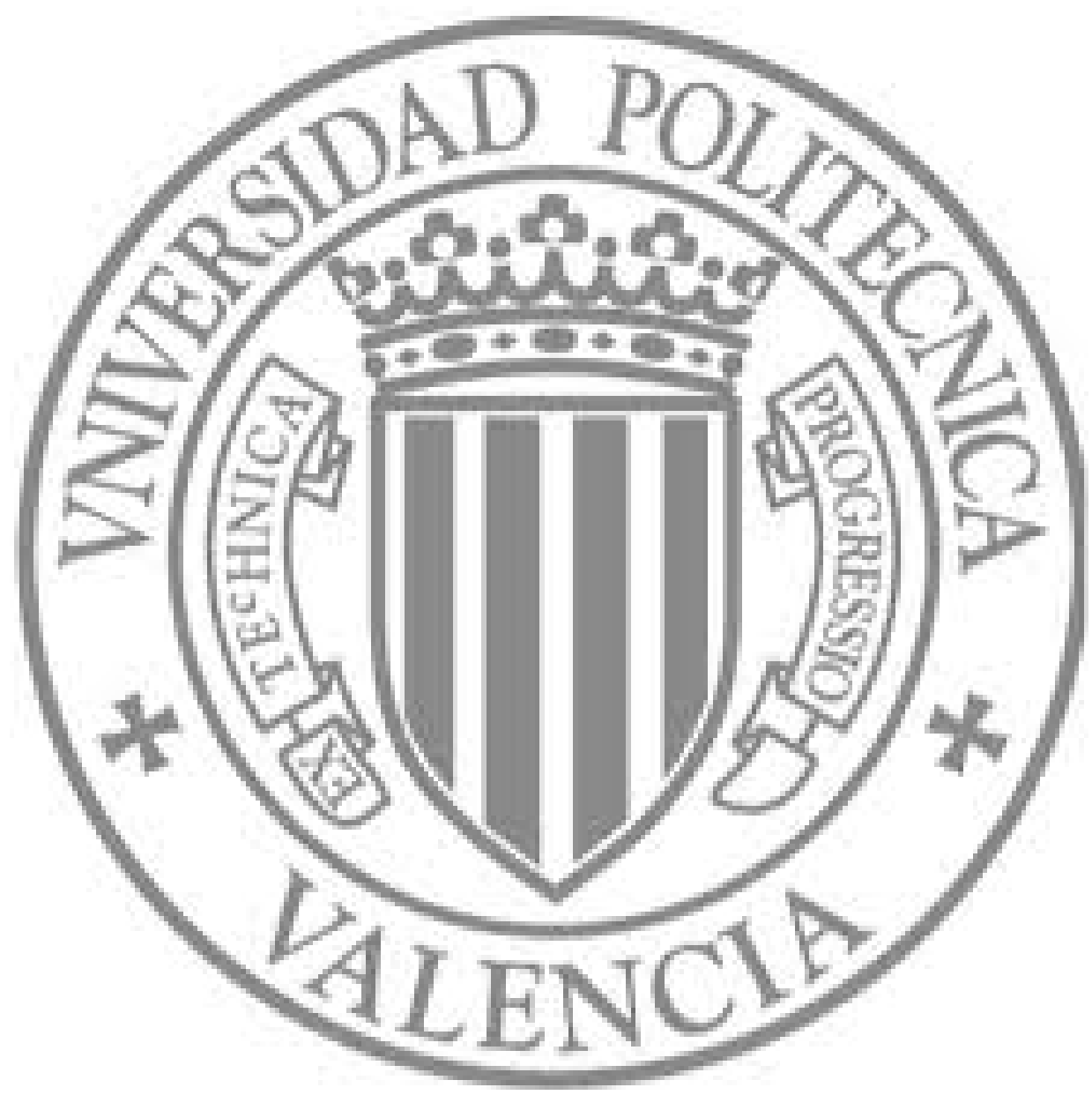

The final publication is available at

http://dx.doi.org/10.1111/str.12019

Copyright Wiley: 12 months 


\title{
Experimental Technique for Measuring the Long-term Transfer Length in Prestressed
}

\section{Concrete}

J.R. Martí-Vargas*, L.A. Caro, P. Serna

ICITECH, Institute of Concrete Science and Technology

Universitat Politècnica de València, 4G, Camino de Vera s/n, 46022, Valencia, Spain

e-mail address:

jrmarti@cst.upv.es; licafo@doctor.upv.es; pserna@cst.upv.es;

*Corresponding author: Tel.: +34 963877007 (ext. 75612); Fax: +34 96 3877569;

e-mail address: jrmarti@cst.upv.es (José R. Martí-Vargas)

\begin{abstract}
This paper presents a proposal of a test setup and methodology for testing the transfer length evolution through time of prestressing reinforcement in pretensioned prestressed concrete members, aimed at providing a basis for standardization. The proposed test method is based on the instantaneous and time-related analysis of the prestressing reinforcement force profile at only one end of a pretensioned prestressed concrete member. The basis of the test method and the requirements of the prestressing frame and its components are presented, as well as the test procedure stages and the measurement devices. The interpretation of the test results and the criteria to determine both the initial and the long-term transfer lengths are explained. A test method application and the equipment for testing seven-wire prestressing strands have been designed. Some experimental results are provided to validate the test. A comparative analysis of test reliability with other existing experimental methods is also included.
\end{abstract}

\section{Keywords}

bond, concrete, prestress, test, transfer length 


\section{Introduction}

Behaviour of structural concrete members strongly depends on the bond between reinforcement and the surrounding concrete. For pretensioned prestressed concrete members, concreting a member is done around the prestressing reinforcement, which has an initial stress that has been previously introduced by tensioning. When concrete reaches enough strength, the prestressing force is transferred by bond to the concrete through the release of prestress. After this release, the prestressing reinforcement force varies from zero at the ends of the member to a constant maximum value (effective prestressing force) in the central zone. The length required to achieve the effective prestressing force is defined as transfer length [1] or transmission length [2]. Figure 1 shows an idealized diagram of the prestressing reinforcement force distribution for a member after release.

Variation in prestressing reinforcement force along the transfer length entails slips between the reinforcement and the concrete (Hoyer effect [3]), and bond stresses are induced. Moreover, the prestress transfer causes instantaneous elastic shortening strains in the concrete member, and the prestressing force diminishes in the reinforcement. Beyond the transfer length, compatibility of the strains between the reinforcement and the concrete exists, and bond stresses are not activated. Consequently, the effective prestressing force in the central zone is slightly lower than the initial force at tensioning.

The concrete strains in a pretensioned prestressed concrete member increase with time (the creep phenomenon), which results in a reduction (losses) of the effective prestressing force. The same effect is caused by the longitudinal shrinkage of concrete. In addition, reinforcement relaxation induces losses of the effective prestressing force. These time- 
dependent effects interact throughout the pretensioned prestressed concrete member's useful life, and a reliable estimation of prestress losses is required to ensure the safety and serviceability of these members [4].

The way in which the prestressing force build-up at the end of the member can be altered after the prestress transfer is by further reinforcement slips [5]. Therefore, since the transfer length is a function of slip distribution, reinforcement and concrete strains, and bond stresses, it follows that a possible long-term effect of the bond behaviour can be achieved and therefore the transfer length can change through time [6].

Transfer length is an important parameter for structural design in pretensioned prestressed concrete [7-9], and it may be determined experimentally. Evaluations of several test results and equations reported in the scientific literature indicate that there is a large scatter in measured and predicted transfer lengths $[10,11]$. Furthermore, several experimental works on the effect of time on transfer lengths report contradictory results $[12,13]$, and there is no standardized method to currently assess such behaviour. Knowledge of concrete materials and properties is essential to better assess their structural applications, and measurement techniques and experimental methods need to be developed [14]. As a result, some attempts to establish a methodology and a convenient test setup to study the transfer length evolution through time in the case of pretensioned prestressed concrete members need to be made.

The purpose of this experimental research is to develop an experimental methodology to measure both the initial and the long-term transfer length of prestressing reinforcement, and therefore the transfer length evolution through time. Bearing this aim in mind, an 
experimental method based on prestressing reinforcement force measurement is proposed, and some test results have been obtained to assess the feasibility of the proposal presented.

\section{Existing experimental methods}

Three experimental methods to frequently determine transfer length are offered which are based on one of the following techniques: prestressing reinforcement end slip determination, longitudinal concrete surface strain profile, and prestressing reinforcement stress (or force).

The first method is based on the Guyon theory [15] and consists in measuring the prestressing reinforcement end slip $(\delta)$ during the prestress transfer. Guyon proposed the expression $L_{t}=$ $\alpha \cdot \delta / \varepsilon_{p i}$ from a theoretical analysis, where $L_{t}$ is the transfer length, $\delta$ is the prestressing reinforcement end slip at the free end of a prestressed concrete member, $\varepsilon_{p i}$ is the initial prestressing reinforcement strain, and the $\alpha$ coefficient represents the shape factor of the bond stress distribution along the transfer length $(\alpha=2$ for uniform bond stress and $\alpha=3$ for linear descending bond stress). Several researchers have proposed different values for $\alpha$ in relation to bond stress distribution along the transfer length based on experimental results and theoretical studies. A brief discussion of the $\alpha$ values available in the literature is presented in [16].

The second method consists in the analysis of the strain profiles on the concrete specimen surface after the prestress transfer versus the distance to the end. Recent experiments have been conducted using an optical strain sensor [17]. However, conventionally strain gauges are attached along the sides of the concrete member prior to release [8]. When the prestressing force is transferred, the compressive strains in the concrete are registered at several distances 
from the ends of the member. These strains profiles follow a similar law to that of the reinforcement force shown in Figure 1. Transfer length can be determined directly from the concrete strain profile [18], by following the Slope-Intercept method [19], or by following the 95\% Average Maximum Strain (AMS) method [8]. Smoothing techniques for these profiles are frequently applied [20, 21].

The third method is based on the determination of the prestressing reinforcement stress (or force) profile. The attachment of electrical resistance strain gauges to the prestressing reinforcement surface to know their stress profile (from the strain measurement by applying the modulus of elasticity of the prestressing reinforcement) is a widespread procedure, but it implies a undesired distortion of the reinforcement-concrete bond phenomenon. As an alternative to avoid this distortion for transfer length determination, a testing technique based on both the direct measurement and the analysis of the prestressing reinforcement force in specimen series with different embedment lengths has been conceived: the ECADA ${ }^{1}$ test method [22], which feasibility has been verified for a short time analysis [23,24].

The application of other sophisticated measurement procedures for transfer length that do not disturb the bond phenomena, such as the radiographic technique [25], photoelasticity [26], contact electrical resistivity [27] or ultrasound [28], have not been developed sufficiently.

\section{Test method approach}

By taking into account that the definition of transfer length is based on the prestressing reinforcement stress [1,2], the two first aforementioned methodologies (longitudinal concrete

\footnotetext{
1 ECADA is the Spanish acronym for "Ensayo para Caracterizar la Adherencia mediante Destesado y Arrancamiento”; in English, "Test to Characterise the Bond by Release and Pull-out"
} 
surface strain profile and the prestressing reinforcement end slip) consist in indirect determinations of transfer length. Consequently, an experimental methodology that makes it possible to measure the stress of prestressing reinforcement is preferable.

Therefore, the direct measurement of prestressing reinforcement stress (or force) at several cross-sections of a pretensioned prestressed concrete member is proposed, as illustrated in Figure 2. Bearing this objective in mind, an Anchorage-Measurement-Access (AMA) system must be placed at the corresponding cross-section of the member to reproduce the prestress transfer only at one end of the member. The typical results after release depend on the specimen embedment length, as follows (see Figure 2): case I for a specimen embedment length shorter than the transfer length; case II for specimen embedment length equal to the transfer length; case III for specimen embedment length longer than the transfer length.

In this work, the ECADA+ test method has been developed as an extended and improved version of the original ECADA test as it allows us to measure the transfer length evolution through time in pretensioned prestressed concrete members. In the design process of the test methodology and the equipment, the following parts have been defined: the basis of the test method, the prestressing frame and its components, the measurement devices, the test procedure stages, AMA system behaviour, the interpretation of a specimen test result, and the representation of the prestressing reinforcement force profile for the complete pretensioned prestressed concrete member.

\section{Basis of the test method}


Given the aim of this work, an adequate test setup must guarantee the application of a prestressing force for a long period of time (a number of months, or even years), and must allow variations of stresses and strains over time and their measurement.

The effective prestressing force decreases with time due to time-dependent effects. If the pretensioned prestressed concrete member is not overloaded, the effective prestressing force remains at a constant value (for a given time) along the central zone of the member. Figure 3 illustrates the idealization of the expected changes on time of the prestressing reinforcement force profile, when no transfer length change takes place (Figure 3a) and when there is a transfer length change through time (Figure 3b).

Given space limitations for testing over a long time, the possibility of having prestressing frames with demountable components to reproduce the prestress transfer phenomenon at only one end of a pretensioned prestressed concrete member has been considered. In this way, the proposed test method is based on the instantaneous and time-related analysis of the prestressing reinforcement force profile at only one end of a pretensioned prestressed concrete member.

\section{Prestressing frame and components}

The measurement of the prestressing reinforcement force at a cross-section of a pretensioned prestressed concrete member requires a prestressing frame to test specimens as a part of one end of the member, as shown in Figure 4. 
The prestressing frame has been designed to introduce some variations starting from the basis of the Keuning equipment test [29] (see Figure 5), which was conceived to apply the push-in technique to simulate bond behaviour in the transfer zone of a pretensioned concrete member. This testing technique consists in the following: the reinforcement tensioning between $\mathrm{A}$ and $\mathrm{B}$; casting the specimen around the prestressing reinforcement to lean on $\mathrm{C}$; and the reinforcement detensioning from A: the movement of reinforcement toward B is produced and bond stresses are achieved because the concrete specimen is supported on reaction plate C.

Figure 6 shows a schematic configuration of the conceived test equipment. According to the basis of the test method and the identified requirements the aforementioned variations are (see Figure 6): a prestressing frame with a length between $A$ and $C$ to allow to test a specimen longer than the transfer length of the prestressing reinforcement in a horizontal manner; a debonded length (by means of a sleeve) to disable the confinement effects at the specimen end to contact $\mathrm{C}$; and a force transducer placed on prestressing reinforcement anchorage $\mathrm{B}$.

The whole series made up by the sleeve, plates C and B, and the support separators placed between plates $\mathrm{C}$ and $\mathrm{B}$, it forms the AMA system which should be designed to simulate the sectional rigidity of the replaced part of the pretensioned prestressed concrete member.

To facilitate tensioning, provisional anchorage, and the detensioning of prestressing reinforcement, a hollow hydraulic actuator with an end-adjustable anchorage device (D) is placed at end $\mathrm{A}$ of the prestressing frame.

\section{Measurement devices}


One desired requirement is that no internal measurement devices are used in order to avoid any distortion of the reinforcement-concrete bond phenomenon.

To determine the prestressing reinforcement force, the strictly required instrumentation is reduced to a hollow force transducer placed between plate B and the anchorage device of the prestressing reinforcement included at the AMA system end. This force transducer makes it possible to measure the prestressing reinforcement force at all times during the test. A hydraulic jack pressure sensor, used to control the force exerted by the hydraulic actuator, completes the instrumentation.

The instrumentation can be complemented with other optional measuring devices, such as displacement transducers to measure the prestressing reinforcement end slip at the free end, and electrical resistance strain gauges or demountable mechanical gauges (DEMEC points) to determine the longitudinal concrete surface strain profile.

\section{Test procedure stages}

With the test equipment mounted as illustrated in Figure 6, the different test procedure stages for a specimen are as follows (Figure 7):

- Placing reinforcement: prestressing reinforcement is lined up to pass through all the holes of the prestressing frame and components (Figure 7a), and both anchorage devices are placed at ends D and B. 
- Tensioning: prestressing reinforcement is tensioned using the hydraulic actuator to pull the anchorage devices by separating D from A (Figure 7b).

- Provisional anchorage: the end-adjustable anchorage device is unscrewed from D until it comes into contact the core of the hydraulic actuator to mechanically block the hydraulic mechanism (Figure 7c). The force supported by the prestressing reinforcement $\left(\mathrm{P}_{\mathrm{H}}\right)$ is anchored, and the pressure circuit is relieved from the hydraulic actuator.

- Specimen concreting: the concrete is mixed and is placed into the previously mounted mould of the prestressing frame around the prestressing reinforcement. After the consolidation operation, the concrete specimen is cured and remains under the selected conservation conditions to achieve the desired concrete properties before the time of testing. Prior to testing, the mould is relieved from the prestressing frame (Figure 7d).

- Releasing the provisional anchorage: the pressure circuit is reconnected to the hydraulic actuator; when the hydraulic actuator recovers the actual prestressing reinforcement force $\left(\mathrm{P}_{0}\right)$, the end-adjustable anchorage device is relieved and withdrawn by screwing toward $\mathrm{D}$ (Figure 7e).

- Detensioning: the hydraulic actuator is unloaded in a controlled manner, and the movement of the prestressing reinforcement from D toward B is produced by a push-in. Bond stresses are activated in the concrete specimen; consequently, the transfer of the prestressing force to the concrete is done: the concrete specimen is pretensioned (Figure $7 \mathrm{f}$ ).

- Stabilisation period.

- Measuring the prestressing force: the initially achieved prestressing force $\left(\mathrm{P}_{\mathrm{I}}\right)$ in the AMA system is measured. For a concrete specimen with an embedment length longer than the transfer length, the $\mathrm{P}_{\mathrm{I}}$ value is the effective prestressing force $\left(\mathrm{P}_{\mathrm{IE}}\right)$.

- Demounting the prestressing frame: the pretensioned prestressed concrete specimen and the AMA system coupled up to it are demounted from the prestressing frame (Figure $7 \mathrm{~g}$ ). 
The concrete specimen, supported by the reaction plate $\mathrm{C}$, remains pretensioned through time.

- Storage of testing specimens: the demounted ensemble is stored under controlled conditions for conservation (Figure 7h).

- Subsequent measuring of the prestressing force: the prestressing force at a certain time $\left(\mathrm{P}_{\mathrm{J}}\right)$ in the AMA system is periodically measured up to an established moment. For a concrete specimen with an embedment length longer than the transfer length, the $\mathrm{P}_{\mathrm{J}}$ value is the effective prestressing force at time $\mathrm{J}\left(\mathrm{P}_{\mathrm{JE}}\right)$.

For these test procedure stages the prestressing reinforcement force sequentially diminishes as follows (for the case of an embedment length being equal to or longer than the transfer length):

- $\mathrm{P}_{\mathrm{H}}$ (introduced prestressing reinforcement force by the hydraulic actuator)

- $\mathrm{P}_{0}$ (prestressing reinforcement force just before detensioning, accounting for small losses by relaxation)

- $\mathrm{P}_{\mathrm{IE}}$ (initial effective prestressing force achieved in the concrete specimen, accounting for instantaneous elastic shortening losses)

- $\mathrm{P}_{\mathrm{JE}}$ (effective prestressing force at time $\mathrm{J}$, accounting for time-dependent losses until time $\mathrm{J}$ )

\section{AMA system response}

After detensioning, the pretensioned concrete specimen has an initial value of the effective prestressing force beyond the transfer length of prestressing reinforcement. This effective prestressing force immediately after detensioning depends on the concrete specimen’s sectional rigidity. Subsequent decreases in the effective prestressing force with time due to 
time-dependent effects also depend on sectional rigidity, among other factors like storage conditions.

The prestressing force is measured in the AMA system. For the effective prestressing force measurement to be reliable, the AMA system should be designed to account for the same prestressing losses as the replaced part of the pretensioned prestressed concrete member. To simulate the concrete specimen's sectional rigidity, it can act on the design of the four aforementioned AMA system components.

From the tensioning to detensioning stages, the AMA system shortening must be the equivalent to the losses due to the instantaneous elastic shortening of the concrete (longitudinal strains). The initial effective prestressing force in the concrete specimen $\left(\mathrm{P}_{\mathrm{IE}, \mathrm{C}}\right)$ can be obtained according to Eq. (1):

$$
P_{I E, C}=\frac{P_{0}}{\left(1+\frac{A_{p} E_{p}}{A_{c} E_{c}}\right)}
$$

where:

$P_{0}$ prestressing reinforcement force just before detensioning

$A_{p}$ prestressing reinforcement area

$E_{p}$ modulus of elasticity of prestressing reinforcement

$A_{c}$ cross-sectional area of the concrete specimen

$E_{c}$ modulus of elasticity of concrete at the testing time

The initial effective prestressing force acting on the AMA system components $\left(\mathrm{P}_{\mathrm{IE}, \mathrm{S}}\right)$ can be obtained according to Eq. (2), where $\Delta \varepsilon_{\mathrm{p}}$ is the prestressing reinforcement strain shortening in the AMA system as a result of the prestress transfer release. 
$P_{I E, S}=P_{0}-A_{p} E_{p} \Delta \varepsilon_{p}$

When considering the response of the AMA system components when moving from the tensioning to the detensioning stages, term $\Delta \varepsilon_{\mathrm{p}}$ can be obtained by Eq. (3) from the geometry and the characteristics of the AMA system materials (shortening defined as positive):

$\Delta \varepsilon_{p}=\frac{1}{L_{A M A}}\left[\Delta L_{d e b}+\delta_{C}-\Delta L_{C B}-\delta_{B}\right]$

where:

$L_{\text {AMA }} \quad$ AMA system length

$\Delta L_{d e b} \quad$ variation in length of debonded length

$\delta_{C} \quad$ variations in the effect of deformations of frame plate $\mathrm{C}$

$\Delta L_{C B} \quad$ variation in length of the support separators between plates $\mathrm{C}$ and $\mathrm{B}$

$\delta_{\mathrm{B}} \quad$ variations in the effect of deformations of frame plate B

Through time, the AMA system behaviour must be also the equivalent to the allowed prestress losses until the considered time J. The effective prestressing force at a certain time in the concrete specimen $\left(\mathrm{P}_{\mathrm{JE}, \mathrm{C}}\right)$ can be obtained according to Eq. (4):

$P_{J E, C}=P_{I E, C}-\Delta P_{\text {shrinkage }}-\Delta P_{\text {creep }}-\Delta P_{\text {relaxation }}$

where:

$\Delta P_{\text {shrinkage }}$ prestressing force losses by concrete shrinkage

$\Delta P_{\text {creep }} \quad$ prestressing force losses by concrete creep

$\Delta P_{\text {relaxation }}$ prestressing force losses by prestressing reinforcement relaxation

The effective prestressing force at a certain time acting on the AMA system components ( $\mathrm{P}_{\mathrm{JE}, \mathrm{S}}$ ) can be obtained according to Eq. (2) by considering $\Delta \varepsilon_{\mathrm{p}}$ as defined in Eq. (3) for the prestressing reinforcement strain shortening in the AMA system at time J. 


\section{AMA system requirements}

The concrete type and its properties at the testing time, as well as the cross-section of the concrete specimen, are parameters which affect the sectional rigidity of the pretensioned prestressed concrete specimen. For the various test conditions, different AMA systems should be designed, but it does not really sound feasible to design an AMA system for each specific test condition. Nevertheless, two requirements must be established:

i) For the determination of the initial transfer length, $P_{\mathrm{IE}, \mathrm{S}} \geq \mathrm{P}_{\mathrm{IE}, \mathrm{C}}$. As Figure 8 shows, the real transfer length would be underestimated if $\mathrm{P}_{\mathrm{IE}, \mathrm{S}}<\mathrm{P}_{\mathrm{IE}, \mathrm{C}}$ (case (b)).

ii) For the determination of the transfer length evolution through time, $\left[\left(\mathrm{P}_{\mathrm{IE}, \mathrm{S}}-\mathrm{P}_{\mathrm{JE}, \mathrm{S}}\right) /\left(\mathrm{P}_{\mathrm{IE}, \mathrm{C}}-\right.\right.$ $\left.\left.\mathrm{P}_{\mathrm{JE}, \mathrm{C}}\right)\right] \leq 1$ to guarantee that $\mathrm{P}_{\mathrm{JE}, \mathrm{S}} \geq \mathrm{P}_{\mathrm{JE}, \mathrm{C}}$ at all times. As Figure 9 shows, it may give rise to uncertain situations which result in the determination of a shortened transfer length at time $\mathrm{J}$ when $\mathrm{P}_{\mathrm{JE}, \mathrm{S}}<\mathrm{P}_{\mathrm{JE}, \mathrm{C}}$ (case (b)).

For these reasons, and despite the ideal AMA system having to possess the same sectional rigidity as the concrete specimen to reliably measure the effective prestressing force, a discontinuity section appears at the border between the concrete specimen and the AMA system as a consequence of the established requirements. This discontinuity gives rise to an overvaluation of the effective prestressing force and the real transfer length (Figure 8 (case (a)) and Figure 9 (case (a)). These overvaluations will be smaller when the AMA system and the sectional rigidity of the concrete specimen are better adjusted.

\section{Interpretation of a specimen test result}


For a specific established test conditions with a properly designed AMA system, the theoretical values of $\mathrm{P}_{\mathrm{IE}, \mathrm{C}}$ and $\mathrm{P}_{\mathrm{IE}, \mathrm{S}}$ can be obtained. After the stabilisation period once detensioning, the initial prestressing force achieved in each specimen $\left(\mathrm{P}_{\mathrm{I}}\right)$ is measured, and one of the following results may be presented:

1) $P_{I}<P_{I E, S}$ : the effective prestressing force is not achieved; the tested specimen has a shorter embedment length than the transfer length.

2) $\mathrm{P}_{\mathrm{I}} \approx \mathrm{P}_{\mathrm{IE}, \mathrm{S}}$ : the effective prestressing force is achieved; the tested specimen has an embedment length equal to or longer than the transfer length.

\section{Prestressing reinforcement force profile}

In the ECADA+ test method, several specimens different only in relation to their embedment length are required and tested under the same conditions. The obtained $\mathrm{P}_{\mathrm{I}}$ values are ordered according to specimen embedment length. The prestressing reinforcement force profile obtained is analyzed. The initial transfer length corresponds to the shorter specimen embedment length with $\mathrm{P}_{\mathrm{I}} \approx \mathrm{P}_{\mathrm{IE}, \mathrm{S}}$ (Figure 10).

To evaluate the transfer length evolution through time, the test specimens whose embedment length is shorter than the transfer length $\left(\mathrm{P}_{\mathrm{I}}<\mathrm{P}_{\mathrm{IE}, \mathrm{S}}\right)$ are rejected. Only the specimens with embedment length equal to or longer than the transfer length $\left(\mathrm{P}_{\mathrm{I}} \approx \mathrm{P}_{\mathrm{IE}, \mathrm{S}}\right)$ are demounted from the prestressing frame and stored under controlled conservation conditions.

The prestressing force at a certain time $\left(\mathrm{P}_{\mathrm{J}}\right)$ in the AMA system is periodically measured. Immediately after storage, all the tested specimens have $\mathrm{P}_{\mathrm{I}} \approx \mathrm{P}_{\mathrm{IE}, \mathrm{S}}$ (again $\left[\mathrm{P}_{\mathrm{J}}=\mathrm{P}_{\mathrm{JE}, \mathrm{S}}\right] \approx \mathrm{P}_{\mathrm{IE}, \mathrm{S}}$ ). Through time, the $\mathrm{P}_{\mathrm{JE}}$ value decreases due to time-dependent effects. As the prestressing 
reinforcement force is directly measured, the set of readings then are taken periodically after the prestress transfer at a certain time include shrinkage, creep, and relaxation prestressing losses. For a certain time $\mathrm{J}$, the subsequent $\mathrm{P}_{\mathrm{J}}$ readings are ranked according to the specimen embedment length, and two different test results may be presented:

a) All test specimens have similar $\mathrm{P}_{\mathrm{J}}$ values (Figure 11a): the effective prestressing force at time $\mathrm{J}$ is achieved $\left(\mathrm{P}_{\mathrm{J}}=\mathrm{P}_{\mathrm{JE}, \mathrm{S}}\right)$; the tested specimens have an embedment length equal to or longer than the transfer length at time J.

b) The $P_{J}$ value is smaller for one or for several test specimen(s) with the shorter embedment lengths, and greater and similar $\mathrm{P}_{\mathrm{J}}$ values are measured in the remaining longer test specimens (Figure 11b): the effective prestressing force at time $\mathrm{J}$ is achieved $\left(\mathrm{P}_{\mathrm{J}}=\mathrm{P}_{\mathrm{JE}, \mathrm{S}}\right)$ in the case the test specimens with greater and similar $\mathrm{P}_{\mathrm{J}}$ values, and transfer length change exists; the test specimens with smaller $\mathrm{P}_{\mathrm{J}}$ values $\left(\mathrm{P}_{\mathrm{J}}<\mathrm{P}_{\mathrm{JE}, \mathrm{S}}\right)$ have a transfer length at time $\mathrm{J}$ longer than the initial transfer length.

The resolution in determining both the initial and the time $\mathrm{J}$ transfer length will depend on the sequence of specimen embedment lengths tested.

\section{Test method application}

A test equipment for testing seven-wire prestressing strands has been designed. In the calculation, strand nominal diameter of $12.7-\mathrm{mm}$, a prestressing force before release $\left(\mathrm{P}_{0}\right)$ of $140 \mathrm{kN}$ (corresponding to 75\% of the nominal strength of prestressing reinforcement) and a concrete with modulus of elasticity $\left(\mathrm{E}_{\mathrm{c}}\right)$ of up to $35000 \mathrm{MPa}$ have been used. Specimen crosssections of $100 \times 100 \mathrm{~mm}^{2}, 80 \times 80 \mathrm{~mm}^{2}$ and $60 \times 60 \mathrm{~mm}^{2}$ with a concentrically single prestressing strand have been considered. 
For this application, the designed equipment includes (Figure 12): a prestressing frame 2000 mm length, with both end plates A and C of 320x320x50 mm; one plate B of 320x200x60 mm; a distance of $250 \mathrm{~mm}$ between plates C and B supported by both 250x120x20 mm welded elements (support separators) to plate B; and a debonded specimen length (sleeve) of $120 \mathrm{~mm}$. In Figure 13, several specimens with different embedment lengths of one of the series under storage conditions are shown.

The instantaneous response of the designed AMA system $\left(\mathrm{P}_{\mathrm{IE}, \mathrm{S}}\right)$ and the $\mathrm{P}_{\mathrm{IE}, \mathrm{S}} \geq \mathrm{P}_{\mathrm{IE}, \mathrm{C}}$ requirement were verified by means of a finite element program for structural analysis. Tensional status and the strains of the AMA system structural elements were checked at the tensioning and detensioning stages. For the equipment test designed in this work, the contributions that represent the four components in the instantaneous response of the AMA system from the tensioning to detensioning stages are: $30 \%$ the debonded length $\left(\Delta L_{d e b}\right)$, and $70 \%$ the plate $\mathrm{C}$ deformation $\left(\delta_{C}\right)$; the effects of $\Delta L_{C B}$ and $\delta_{B}$ (by the decompression of plate B and its welded elements from the tensioning to detensioning stages) are insignificant.

It is very complex to exactly know in advance the AMA system response with time $\left(\mathrm{P}_{\mathrm{JE}, \mathrm{S}}\right)$. The debonded length is affected by the losses of pretensioned prestressed concrete specimen, and a creep phenomenon of the AMA system structural elements can be expected, which is counteracted by a slight increase in the AMA system length due to the diminished effective prestressing force with time.

However, previously knowing the exact value of $\mathrm{P}_{\mathrm{JE}, \mathrm{S}}$ is not strictly necessary within an application: when testing specimens with the same test conditions, and whose embedment 
length only varies, the maximum possible value in the prestressing reinforcement force profile for each time $\mathrm{J}$ is always the effective prestressing force $\mathrm{P}_{\mathrm{JE}}$ (measured in the AMA system, corresponding to $\left.\mathrm{P}_{\mathrm{JE}, \mathrm{S}}\right)$. As the $\mathrm{P}_{\mathrm{IE}, \mathrm{S}} \geq \mathrm{P}_{\mathrm{IE}, \mathrm{C}}$ requirement has been verified, further changes in the AMA system response would be smaller than the changes from the tensioning and detensioning stages: after detensioning, the changes in $\delta_{C}, \Delta L_{C B}$ and $\delta_{B}$ would be insignificant, and only the debonded length component would be influenced by prestressing losses of the pretensioned prestressed concrete specimen. In this way, the $\mathrm{P}_{\mathrm{JE}, \mathrm{S}} \geq \mathrm{P}_{\mathrm{JE}, \mathrm{C}}$ requirement is guaranteed. Therefore, all the specimens with an embedment length equal to or longer than the transfer length at time $\mathrm{J}$ would be shown as $\mathrm{P}_{\mathrm{J}}$ (measured) $=\mathrm{P}_{\mathrm{JE}}=\mathrm{P}_{\mathrm{JE}, \mathrm{S}}$ (previously unknown), and the specimens whose embedment length is shorter than the transfer length at time $\mathrm{J}$ would be shown as $\mathrm{P}_{\mathrm{J}}$ (measured) $<\mathrm{P}_{\mathrm{JE}}$ (now also measured $)=\mathrm{P}_{\mathrm{JE}, \mathrm{S}}$.

\section{Experimental test method validation}

Once the test methodology was established and the corresponding equipment was defined to carry out tests on the pretensioned prestressed concrete specimens, an experimental program has been developed [30] at the ICITECH laboratories covering different test conditions to validate the transfer length test setup and the methodology presented herein. The main variables considered have been: concrete type, cross-section of specimens, and release age

and method. By way of example, the results from two series of test specimens are presented in Figure 14. The same concrete was used for both series, and only the prestress transfer release age was varied.

Prestressing reinforcement force curves for both cases, with time, are shown in Figure 14. The time-dependent behaviour only shows changes regarding the effective prestressing force for 
the first case [(a), 24-hour release age], while the second tested case [(b), 12-hour release age] has also transfer length evolution through time.

As it can be seen in Figure 14, the test method is capable of distinguishing the time-dependent bond behaviour of pretensioned prestressed concrete specimens, and of registering the transfer length of prestressing reinforcement at detensioning and during the storage stage to analyze the possible transfer length evolution through time. Further analyses to determine the test conditions and variables which do or do not result in a transfer length change are needed.

The obtained results were compared with the results based on the longitudinal concrete surface strain profile and on the prestressing reinforcement end slip analysis.

Figure 15 offers the test results of the both the $1350 \mathrm{~mm}$ embedment length specimens (for the 24-hour and 12-hour release ages). The transfer lengths obtained by means of the proposed test method is also indicated (450 $\mathrm{mm}$ and 650-700 mm, respectively). Figure 15 show that, given the slope of the first part of the curve, it may be assumed that the plateau begins at $400 \mathrm{~mm}$ after detensioning for a 24-hour release age, and it may also be interpreted that the plateau begins between $400 \mathrm{~mm}$ and $600 \mathrm{~mm}$ after one year for a 24-hour release age. Moreover for the 12-hour release age, another interpretation could be that the plateau begins between $550 \mathrm{~mm}$ and $700 \mathrm{~mm}$, and that the transfer length change does not appear clearly after one year. Consequently, the proposed test method enables us to determine transfer length more accurately than the method based on the longitudinal concrete surface strain profile.

Figure 16 depicts the transfer length results obtained by the proposed test for each release age series, as well as the transfer lengths obtained from the free end slips by applying Guyon's 
expression [20]. This expression has been applied to free end slips registered after detensioning and after one year in specimens with an embedment length equal to or longer than the transfer length by applying the $\alpha=2$ and $\alpha=3$ coefficients. The amplitude of the transfer length intervals is variable for the different embedment lengths and varies with time, as shown in Figure 16. The results obtained from the slip vary vastly by giving initial transfer length values of between $233 \mathrm{~mm}$ and $731 \mathrm{~mm}$ (for the 24-hour release age), and of between $361 \mathrm{~mm}$ and $778 \mathrm{~mm}$ (for the 12-hour release). For the long-term transfer length, the values obtained from the slip are between $255 \mathrm{~mm}$ and $709 \mathrm{~mm}$ (24-hour release age), and between $393 \mathrm{~mm}$ and $804 \mathrm{~mm}$ (12-hour release age). The results obtained by the proposed test method fall within the intervals in all cases. Therefore, the proposed test method provides more reliable results than those obtained by applying the method based on the prestressing reinforcement end slip.

\section{Conclusions}

The main conclusions drawn from this experimental research work are:

- An experimental methodology to study transfer length evolution through time, and to determine both the initial and the long-term transfer lengths of prestressing reinforcement in pretensioned prestressed concrete members has been conceived.

- The proposed test method is based on the instantaneous and time-related analysis of the prestressing reinforcement force profile at only one end of a pretensioned prestressed concrete member.

- The test method presented herein optimizes space, guarantees the pretensioned prestressed condition for whatever lapse of time desired, and offers the possibility of testing more than 
one element in the same prestressing frame by demounting one part of the structural elements.

- The instrumentation used in the test is simple and recoverable, and an internal measuring device has not been used in the test specimens in order to not distort the bond phenomenon.

- The experimental results obtained by using the equipment and methodology proposed herein allow an analysis of the transfer length evolution through time of pretensioned prestressed concrete members, based on the measurement of the prestressing reinforcement force.

- The proposed methodology makes it possible to study of the influence of time-dependent effects on the transfer length of variables such as: type of concrete, prestressing reinforcement type, specimen cross-section, testing age, level of prestress, and others such as storage conditions.

- This methodology for testing transfer length is susceptible of being standardized. Standardization criteria can be defined in two ways: to analyze the transfer length evolution through time in a determined set of conditions (for a determined concrete type, prestress level, etc.), or to characterize the behaviour of a prestressing reinforcement type under standard conditions (materials and concrete mix design, release age, storage conditions, etc.).

- The feasibility of applying this transfer length test setup and methodology has been verified in an experimental program to assess the long-term bond behaviour of pretensioned prestressed concrete specimens. The experimental results for two different test conditions have been shown to support this statement.

- The proposed test method has provided more reliable results than procedures based on measuring the longitudinal strain in concrete or free end slip measurements.

\section{Acknowledgements}


Funding for this experimental research work was provided by the Spanish Ministry of Education and Science and ERDF (Projects BIA2006-05521 and BIA2009-12722). Tests were conducted in the Institute of Concrete Science and Technology (ICITECH), Universitat Politècnica de València (Spain). 


\section{References}

[1] American Concrete Institute (2011) ACI 318-11. ACI Committee 318: Building Code Requirements for Reinforced Concrete. American Concrete Institute, Farmington Hills, MI. [2] International Federation for Structural Concrete (2010) MODEL CODE 2010 (First complete draft). FIB Bulletin n ${ }^{\circ} 55$, Vol. 1, International Federation for Structural Concrete Lausanne.

[3] Hoyer, E. and Friedrich, E. (1939) Beitrag zur frage der haftspannung in eisenbetonbauteilen. Beton und Eisen 50(9), 717-736.

[4] Rao, K.B., Anoop, M.B., Sreeshylam, P., Sridhar, S., Kesavan, K. and Ravisankar, K. (2011) Assessment of pre-stress losses in instrumented pre-stressed concrete beams using stochastic analysis. Strain $\mathbf{4 7}, 175-188$.

[5] Base, G.D. (1957) Some tests on the effect of time on transmission length in pretensioned concrete. Mag. Concr. Res. 4, 73-82.

[6] Cousins, Th.E., Johnston, D.W. and Zia, P. (1990) Transfer length of epoxy-coated prestressing strand. ACI. Mat. J. 87(3), 193-203.

[7] Grace, N.F. (2000) Transfer length of CFRP/CFCC strands for double-T girders. PCI J. 45(5), 110-126.

[8] Russell, B.W. and Burns, N.H. (1996) Measured transfer lengths of 0.5 and 0.6 in. strands in pretensioned concrete. PCI J. 41(5), 44-65.

[9] Barnes, R.W., Grove, J.W. and Burns, N.H. (2003) Experimental assessment of factors affecting transfer length. ACI Struct. J. 100(6), 740-748.

[10] Martí-Vargas, J.R., Arbeláez, C.A., Serna-Ros, P., Navarro-Gregori, J. and PallarésRubio, L. (2007) Analytical model for transfer length prediction of $13 \mathrm{~mm}$ prestressing strand. Struct. Eng. Mech. 26(2), 211-229. 
[11] Floyd, R.W., Howland, M.B. and Hale, W.M. (2011) Evaluation of strand bond equations for prestressed members cast with self-consolidating concrete. Eng. Struct. 33, 2879-2887.

[12] Weerasekera, I. (1991) Transfer and Flexural Bond in Pretensioned Prestressed Concrete. PhD Thesis, University of Calgary, UMI Dissertation Services.

[13] International Federation for Structural Concrete (2000) Bond of reinforcement in concrete. State of the art report. FIB Bulletin $\mathrm{n}^{0} 10$. Lausanne

[14] Arango, S., Serna, P., Martí-Vargas, J.R. and García-Taengua, E. (2011) A test method to characterize flexural creep behaviour of pre-cracked FRC specimens. Exp Mech. 52: 10671078.

[15] Guyon, Y. (1953) Béton Précontrainte. Étude Théorique et Experiméntale. Eyrolles, Paris.

[16] Martí-Vargas, J.R., Arbeláez, C.A., Serna-Ros, P. and Castro-Bugallo, C. (2007) Reliability of transfer length estimation from strand end slip. ACI Struct. J. 104(4), 487-494. [17] Wu, C.H., Zhao, W., Beck, T. and Peterman, R. (2011) Optical sensor developments for measuring the surface strains in prestressed concrete members. Strain 47, 376-386.

[18] Mahmoud, Z.I., Rizkalla, S.H. and Zaghloul, E.R. (1999) Transfer and development lengths of carbon fiber reinforcement polymers prestressing reinforcing. ACI Struct. J. 96(4), 594-602.

[19] Deatherage, J.H., Burdette, E. and Chew, Ch.K . (1994) Development length and lateral spacing requirements of prestressing strand for prestressed concrete bridge girders. PCI J. 39(1), 70-83.

[20] Lu, Z., Boothby, Th.E., Bakis, Ch,E, and Nanni, A. (2000) Transfer and development lengths of FRP prestressing tendons. PCI J. 45(2), 84-95. 
[21] Kahn, L.F., Dill, J.C. and Reutlinger, C.G. (2002) Transfer and development length of 15-mm strand in high performance concrete girders. J. Struct. Eng. 128(7), 913-921. [22] Martí-Vargas, J.R., Arbeláez, C.A., Serna-Ros, P., Fernández-Prada, M.A. and MiguelSosa, P.F. (2006) Transfer and development lengths of concentrically prestressed concrete. PCI J. 51(5), 74-85.

[23] Martí-Vargas, J.R., Serna, P., Navarro-Gregori, J. and Bonet, J.L. (2012) Effects of concrete composition on transmission length of prestressing strands. Constr. Build. Mater. 27(1), 350-356.

[24] Martí-Vargas, J.R., Serna, P., Navarro-Gregori, J. and Pallarés, L. (2012) Bond of 13 mm prestressing steel strands in pretensioned concrete members. Eng. Struct. 41, 403-412. [25] Evans, R.H. and Robinson, W.R. (1955) Bond stresses in prestressed concrete from Xray photographs. P. I. Civil Eng. 6(14), 212-235.

[26] Linger, D.A. and Bhonsle, S.R. (1963) An investigation of transfer length in pretensioned concrete using photoelasticity. PCI J. 8(4), 13-30.

[27] Fu, X. and Chung, D.D.L. (1998) Effects of water-cement ratio, curing age, silica fume, polymer admixtures, steel surface treatments, and corrosion on bond between concrete and steel reinforcing bars. ACI Mat. J. 95(6), 725-734.

[28] Chen, H. and Wissawapaisal, K. (2001) Measurement of tensile forces in a seven-wire prestressing strand using stress waves. J. Eng. Mech. 6, 599-606.

[29] Keuning, R.W., Sozen, M.A. and Siess, C.P. (1962) A study of anchorage bond in prestressed concrete. Structural Research Series No. 251, University of Illinois, IL. [30] Caro L. (2012) Comportamiento adherente diferido de armaduras pretesas en el hormigón (Long-term bond behaviour of reinforcement in pretensioned prestressed concrete), PhD Thesis, Polytechnic University of Valencia, Valencia (Spain). 


\section{LIST OF FIGURE CAPTIONS}

Figure 1: Idealized prestressing force diagram in a pretensioned prestressed concrete member after release

Figure 2: Idealization of the typical prestressing force results at several cross-sections of a pretensioned prestressed concrete member

Figure 3: Idealization of the expected variation through time of the prestressing force profile, (a) without a transfer length change, (b) with a transfer length change

Figure 4: View of a specimen as a part of one end of the pretensioned prestressed concrete member

Figure 5: Push-in test based on Keuning et al. [29]

Figure 6: Scheme of the test equipment

Figure 7: Test procedure stages

Figure 8: Overvaluation and undervaluation of the initial transfer length

Figure 9: Overvaluation and undervaluation of the long-term transfer length

Figure 10: Initial transfer length determination according to the ECADA+ test method

Figure 11: Long-term transfer length determination according to the ECADA+ test method

Figure 12: General view of the prestressing frames designed

Figure 13: General view of the stored specimens

Figure 14: Test results for some specimens whose release age varies only, (a) 24-hour release age, (b) 12-hour release age

Figure 15: Longitudinal concrete surface strain profiles for the specimens whose release age only varies, (a) 24-hour release age, (b) 12-hour release age

Figure 16: Comparison of the measured transfer lengths with calculated values according to Guyon’s expression, (a) 24-hour release age, (b) 12-hour release age 